九州大学学術情報リポジトリ

Kyushu University Institutional Repository

Estimating Thermal Behavior and Analyzing

Evolved Species of Adhesives Through

Thermogravimetric Analysis combined with

Spectrometric Techniques

Lin, Han Chien

Department of Forest Products Science, College of Agriculture, Naationa Chiayi University

Ohuchi, Takeshi

Laboratory of Wood Material Technology, Division of Biomaterial Science, Department of Forest and Forest Products Sciences, Faculty of Agriculture, Kyushu University

Murase, Yasuhide

Laboratory of Wood Material Technology, Division of Biomaterial Science, Department of Forest and Forest Products Sciences, Faculty of Agriculture, Kyushu University

https://doi.org/10.5109/4606

出版情報: 九州大学大学院農学研究院紀要. 49 (2)，pp.449-459，2004-10-01. Faculty of Agriculture, Kyushu University

バージョン :

権利関係 : 


\title{
Estimating Thermal Behavior and Analyzing Evolved Species of Adhesives through Thermogravimetric Analysis combined with Spectrometric Techniques
}

\author{
Han Chien LIN ${ }^{1}$, Takeshi OHUCHI and Yasuhide MURASE* \\ Laboratory of Wood Material Technology, Division of Biomaterial Science, \\ Department of Forest and Forest Products Sciences, Faculty of \\ Agriculture, Kyushu University, Fukuoka 812-8581, Japan \\ (Received June 30, 2004 and accepted July 13, 2004)
}

\begin{abstract}
Four types of commercial adhesives, urea formaldehyde resin adhesives (UF), melamine-urea formaldehyde copolymer resin adhesives (MUF), phenol formaldehyde resin adhesives (PF) and diphenylmethane diisocyanate adhesives (MDI) were studied, by first using thermogravimetric analysis (TGA) alone, and then by using thermogravimetric analysis with infrared spectrometry (TGA-IR). Results obtained from the TGA tests found that MDI exhibited the highest initial decomposition at a temperature of $297^{\circ} \mathrm{C}$ and better overall thermo-stability than the other types of adhesives. PF and MDI provided a better yield of char at about 24.88 and $20.61 \mathrm{wt} \%$, respectively, at $850^{\circ} \mathrm{C}$. This showed that their thermal behavior was better than that of UF ( $5.40 \mathrm{wt} \%)$ or MUF $(6.99 \mathrm{wt} \%)$. The IR response of all adhesives in the TGA-IR tests showed that the absorbance of UF, MUF and MDI was higher than that of PF; this indicated that the concentration of evolved species of PF was less than that of MDI, and less than that of the urea copolymer series adhesives, UF and MUF. It has been suggested that PF is the most environmentally friendly adhesive, because it has the least environmental impact when used in many industrial and domestic applications, such as for structural members in furniture or architecture. These results, when compared to the molecular structures of the adhesives, enabled us to point out the kinds of evolved species (functional bases or the change in molecular structures) for referencing the thermo-degradation processes of the adhesives. Using TGA-IR, to analyze the thermal behavior of 4 types of adhesives, in combination with TGA. analysis, has led to useful results, involving the identification of pyrolysis products.
\end{abstract}

\section{INTRODUCTION}

In the event of a fire, smoke inhalation usually presents the gravest danger for survivors. This is because, those who find themselves in a burning building, may experience post-exposure pulmonary (lung) complications, which can lead to subsequent injury or death from the inhalation of emitted gases and complications from thermal burns (Baker, 1991). Combustion toxicology embraces the nature, severity and the time course of adverse effects produced from exposure to fire-generated toxic species (Hartzell, 1996).

The thermal behavior (pyrolysis, thermal decomposition or combustion) of every combustible material or product produces a toxic smoke atmosphere. This toxic smoke atmosphere, in sufficiently high concentrations, presents a hazard to exposed animals and humans. 'These hazards include impaired vision, due to eye irritants; narcosis from

\footnotetext{
${ }^{1}$ Department of Forest Products Science, College of Agriculture, National Chiayi University, Chiayi, Taiwan, ROC.

* Corresponding author (E-mail: ymurase@agr.kyushu-u.ac.jp)
} 
inhalation of asphyxiates; and irritation to the upper or lower respiratory tracts. These effects often occur simultaneously, and contribute to physical incapacitation, loss of motor coordination, faulty judgment, disorientation, restricted vision and panic (Hartzell, 1996).

Currently, studies concerned with so called "eco-materials" and the environment, are increasingly focused on the effective or functional use of natural resources, the recycling of industrial wastes and the development of new environmentally friendly materials (Okuma, 1998). Methods, to recycle discarded materials, are encouraged (renewable resources), including the development of new wood-based materials in accordance with the principle of cascade utilization (Akiyama, 1998; Kuwahara, 1996). However, the structural members of furniture or buildings are generally manufactured using extra-strength adhesives, which are widely utilized in many industrial and domestic applications. Such discarded materials are extremely difficult to recycle and use as a raw material, because they do not possess a critical bonding quality, as do virgin wood chips or particles (Kobayashi et al., 2000; Shibuwaza, 2000). In many cases the final treatment, for this type of waste, is to remove it from service and burn it (Jang, 1997). Therefore, it is necessary to determine the thermal behavior of these organic adhesives during combustion, including such things as, pyrolysis temperature, compounds emitted, total amount of volatiles evolved and the amount of char formed (Kercher et al., 2001).

In order to provide an understanding of the fundamental thermal behavior of these adhesives, this study comprised two categories of examination. The first was connected to the study of thermal decomposition, by examining the effectiveness of the pyrolysis of adhesives, using thermogravimetric analysis (TGA). The second applied thermogravimetric analysis with infrared spectrometry (TGA-IR), to monitor the effectiveness, on an analytical scale, of the four adhesives and also to examine the emissions of certain compounds in each particular analysis. The commercial adhesives tested included urea formaldehyde resin adhesives (UF), melamine-urea formaldehyde copolymer resin adhesives (MUF), phenol formaldehyde resin adhesives (PF) and diphenylmethane diisocyanate adhesives (MDI). Our goal in this research was to acquire fundamental knowledge of the thermal behavior of adhesives, while at the same time obtaining an air pollution reference for gas emissions.

\section{MATERIALS AND METHODS}

\section{Adhesives}

The commercial adhesives used in this study are summarized as follows:

a. Urea formaldehyde resin adhesives (UF Resin-180, UF);

b. Melamine-urea formaldehyde copolymer resin adhesives (MUF PB-1230, MUF);

c. Phenol formaldehyde resin adhesives (PF PB-1310, PF);

d. Diphenylmethane diisocyanate adhesives (MDI PB-1605, MDI).

These adhesives were provided by Oshika Shinko Co. Ltd., Fukuoka. The percentage of resin solids obtained from the adhesives was 61.2 (UF), 60.3 (MUF), 45.5 (PF) and 96.3 (MDI), after they had been placed into convection ovens at $105^{\circ} \mathrm{C}$ for over $3 \mathrm{~h}$. These air-dried UF, MUF, PF and MDI specimens were individually tested, using thermogravimetric analysis, to determine the thermal behavior of adhesives; thermogravimetric 
analysis, with infrared spectrometry, was used to examine the emissions of certain compounds (evolved species) during the pyrolysis of the adhesives.

\section{Thermogravimetric analysis (TGA)}

Thermogravimetric analysis (TGA) is a common technique for measuring the weight change of a material as a function of temperature. Throughout this research project, TGA was carried out using a Perkin-Elmer TGA 1, fully supported by computer-controlled software options, from Perkin-Elmer Thermal Analysis Systems, for control and data handling. The samples, approximately $5.0-10.0 \mathrm{mg}$ in weight, were placed into an open experimental sample pan, and suspended from a sensitive microbalance. A furnace surrounded the sample to provide accurate heating from 50 to $850^{\circ} \mathrm{C}$, while the measurement was taking place. In order to isolate the pyrolysis step, considered the most important step in the burning process for materials or products, a nitrogen atmosphere was selected for TGA analysis (Hsu et al., 2000). All runs were purged in nitrogen atmosphere, at a flow rate of $50 \mathrm{ml} / \mathrm{min}$, with a heating rate of $20^{\circ} \mathrm{C} / \mathrm{min}$. The thermal behavior for the four types of adhesives was then tested.

\section{Thermogravimetric analysis with Infrared spectrometry (TGA-IR)}

TGA, described in the previous section, is a quantitative technique, which does not identify evolved compounds. To understand the evolved species produced by the pyrolysis of the four types of adhesives, analysis was carried out using a TGA (Perkin-Elmer Pyris 7 TGA model), linked to a secondary method of analysis, Fourier-Transform Infrared Spectroscopy (using a Perkin-Elmer FTIR), which was able to identify the evolved species during the TGA measurements (Statheropoulos, 2000). The TGA and FTIR (TGA-IR) were connected using a transfer line with a continuous scanner in a gaseous cell. The Infrared spectrometric (IR) response data was recorded by a personal computer. The time-based software obtained and analyzed the evolved species as they occurred. The samples, weighing about $5.0 \mathrm{mg}$., were placed in an open pan and suspended from a sensitive microbalance in the Pyris 7 TGA model. The conditions were set the same as for the Perkin-Elmer TGA 1, described above, for heating and nitrogen flow rates. The evolved species analysis was performed on the TGA-IR. However, the IR response obtained for various evolved species using the TGA-IR appeared about $10 \mathrm{sec}$ later, when compared to the TGA traces. In order to discuss the criteria and limitations of both TGA-IR and TGA for each particular analysis, and to ensure accurate results, it was necessary to carefully study and compare the results obtained between the pyrolysis temperature (obtained from TGA) and the decomposition time of the evolved species from the IR response (obtained from TGA-IR).

\section{RESULTS AND DISCUSSION}

\section{Thermal decomposition of adhesives}

TGA is an established technique, used in the quantification of weight changes within a material, as a function of temperature or time. To comprehend the thermal behavior (pyrolysis, thermal decomposition) of the four types of adhesives, the adhesive specimens were measured by TGA, after being air-dried at ambient temperatures. Decomposition 
profiles were obtained while heating at a rate of $20^{\circ} \mathrm{C} / \mathrm{min}$ in nitrogen, between $50^{\circ} \mathrm{C}$ (initial temperature) and $850^{\circ} \mathrm{C}$ (end temperature). The relationships of TGA and DTG curves between temperature and weight loss, and the derivative weight for each adhesive specimen, UF, MUF, PF and MDI, are shown in Fig. 1.
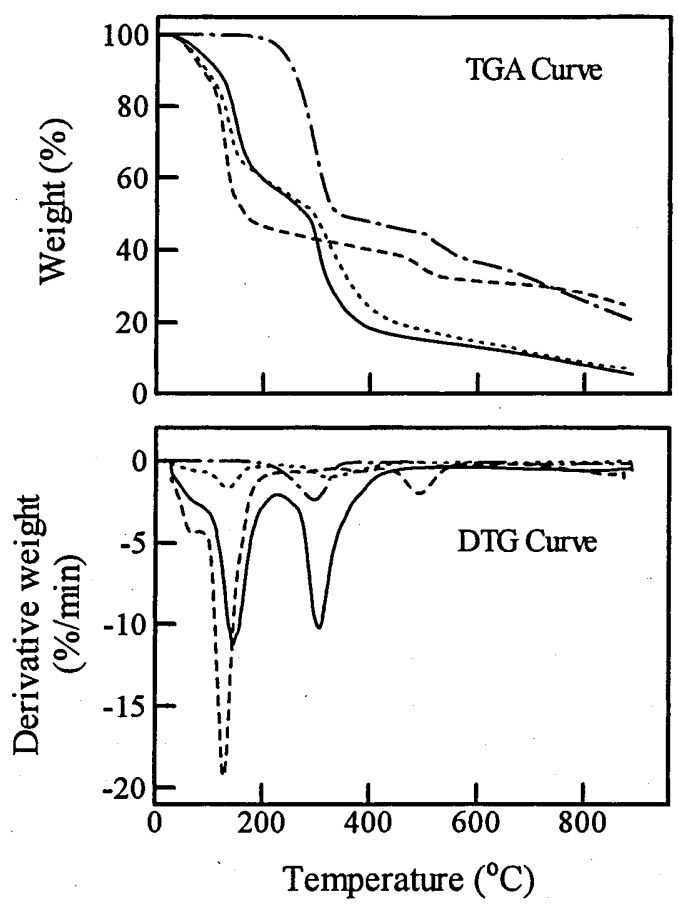

Fig. 1. TGA and DTG curves for 4 types of adhesives (UF, MUF, PF and MDI) in nitrogen at $20^{\circ} \mathrm{C} / \mathrm{min}$.

Symbols: — : UF, .......: MUF, ---: PF, -.- : MDI.

Notes: Urea formaldehyde resin adhesives (UF), Melamine-urea formaldehyde copolymer resin adhesives (MUF), Phenol formaldehyde resin adhesives (PF), Diphenylmethane diisocyanate adhesives (MDI).

As expected, the four types of adhesives typically showed gradual weight loss. The thermogram, resulting from the analysis of UF (solid line) and MUF (dotted line), showed that there were two subtle changes (shoulders) at temperatures of 50 to $390^{\circ} \mathrm{C}$, suggesting that both had almost identical initial (the first sharp step) and secondary decomposition temperatures, because UF and MUF are copolymers. The onset of weight loss under nitrogen was observed at temperatures of 127 and $285^{\circ} \mathrm{C}$ for UF and at temperatures of 109 and $290^{\circ} \mathrm{C}$ for MUF. This is supported by the derivative (DTG) curve, which showed two peaks at temperatures of 145 and $306^{\circ} \mathrm{C}$ for UF and at temperatures of 132 and $321^{\circ} \mathrm{C}$ 
for MUF (the bottom of Fig. 1). Considering the amount of char for both UF and MUF, at a temperature of $850^{\circ} \mathrm{C}$, UF was $5.40 \mathrm{wt} \%$ and MUF was $6.99 \mathrm{wt} \%$; these were lower than the other two (PF and MDI).

The adhesive specimen weight for PF (dash line) was significantly less at temperatures between $50^{\circ} \mathrm{C}$ and $500^{\circ} \mathrm{C}$ in the TGA tests; the weight loss for MDI (dash-dot-dash line) was significant at temperatures from 200 to $400^{\circ} \mathrm{C}$. This indicates that the chemical structure, in the molecular chain, or chemical composition, of PF and MDI is different. For the onset of weight loss, the temperature was at 61,116 and $481^{\circ} \mathrm{C}$ for $\mathrm{PF}$, and at 247 , 501 and $541^{\circ} \mathrm{C}$ for MDI. The DTG curve was specified in three peaks at temperatures of 65,129 and $493{ }^{\circ} \mathrm{C}$ for $\mathrm{PF}$, and 297,514 and $547^{\circ} \mathrm{C}$ for MDI (the bottom of Fig. 1). The amount of char for PF and MDI left $24.88 \mathrm{wt} \%$ and $20.61 \mathrm{wt} \%$, respectively, of stable residue, at a temperature of $850^{\circ} \mathrm{C}$.

The above results, obtained from the TGA tests, showed that MDI had the highest initial decomposition temperature $\left(297^{\circ} \mathrm{C}\right)$, and better overall thermal stability, than the others. Moreover, when comparing the char of the four types of adhesives, PF and MDI provided better yield of char at $850^{\circ} \mathrm{C}$. This showed that the thermal behavior of $P F$ and MDI is better than that of UF and MUF, as the proposed action mechanism is based on the charred layer acting as a physical barrier, which slows down heat, and results in mass transfers between the gas and condensation phases (Camino, 1993; Hornsby, 1996; Zhu, 2001).

\section{Infrared spectrometric response of adhesives}

Figure 2 shows the Infrared spectrometric (IR) response of the four types of adhe-
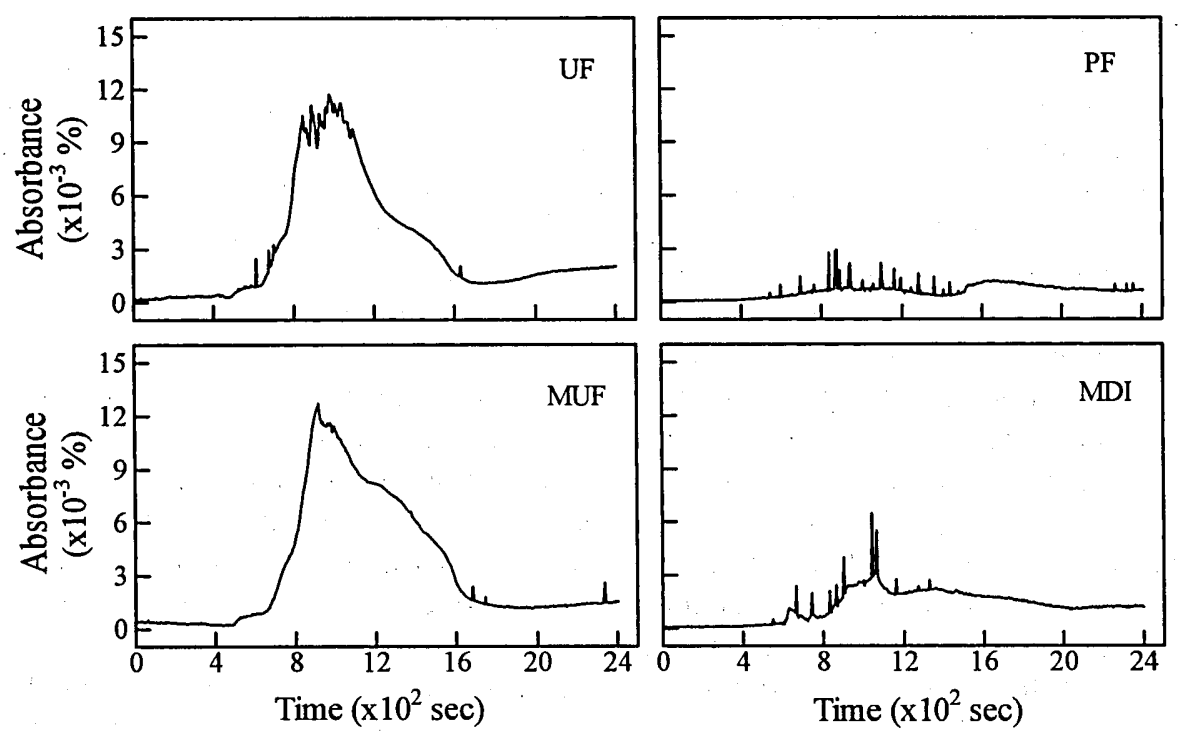

Fig. 2. IR response of 4 types of adhesives (UF, MUF, PF and MDI) from TGA-IR analysis. Note: Abbreviations of UF, MUF, PF and MDI are the same as Figure 1. 
sives in the TGA-IR measurements. The change in absorbance (concentration of evolved species \%) corresponded to the increase in decomposition time for the four adhesives. The concentration of evolved species for the IR response of UF and MUF increased slowly, to about $620 \mathrm{sec}$, from the start of decomposition. Subsequently, this increasing tendency rose linearly to about $900 \mathrm{sec}$. The high point of absorbance was shown as $981.3 \mathrm{sec}$ for UF and $906.6 \mathrm{sec}$ for MUF. After that, the change in concentrations of evolved species tended to decrease, until the end of decomposition. Furthermore, the IR response of UF, between 840 and $1080 \mathrm{sec}$, showed a greater mountain peak. This suggested that the concentration of evolved species for UF is higher than for MUF.

The concentration of evolved species from the IR response of PF was similar to a hillock with several independent plants, ranging from $380 \mathrm{sec}$ to the end of decomposition. The high point of absorbance occurred at $864.8 \mathrm{sec}$. The concentration of evolved species in the IR response of MDI increased slowly to about $600 \mathrm{sec}$ from the beginning of decomposition. Subsequently, the time change in the concentration of evolved species became the ridge of a house. The high point of absorbance occurred at $1055.2 \mathrm{sec}$.

Comparing the IR response of all adhesives, the absorbance levels for UF, MUF and MDI were higher than for PF. This indicated that the concentration of evolved species of $\mathrm{PF}$.was less than those of MDI or the urea copolymer series adhesives, UF and MUF. Of them all, $\mathrm{PF}$ was considered to be the best adhesive with the least environmental impact. A similar conclusion was reached in previous research (Lin et al., 2001), which indicated that $\mathrm{PF}$ was the most environmentally friendly adhesive for manufacturing particleboard, because the emission contents (such as carbon monoxide, nitrogen monoxide and sulfur dioxide) of PF were less than UF, MUF and MDI, when the used particleboard was destroyed by combustion.

\section{TGA-IR spectra and typical structure of adhesives}

In recent years, there has been much attention paid to the use of adhesives (formaldehyde copolymer compounds), because, during combustion, they emit toxic gases and corrosive smoke; exposure to these toxic and acidic fumes can cause great harm to people and can also damage costly equipment (Ladomersky, 2000). With the use of TGA-IR, it is possible to simultaneously monitor evolved species; pyrolysis temperature and concentrations formed (absorbance), as well as the evolution profile of certain compounds. Moreover, IR spectrometry is a common means of evaluating a functional base when a material undergoes degradation.

The evolution of decomposition time (or pyrolysis temperature) on absorbance and wavenumbers (basically, IR spectra) for the various types of adhesive specimens (UF, MUF, PF and MDI) is shown in Fig. 3. The distribution of wavenumbers at the end of each $120 \mathrm{sec}$, during decomposition time, was analyzed. The results obtained, summarized below, analyze the data between the TGA curve (pyrolysis temperature) in the TGA tests and TGA-IR response (decomposition time along with wavenumbers and absorbance) in the TGA-IR measurement.

For TGA-IR spectra of UF (the top left of Fig. 3), the $\mathrm{CO}_{2}$ peak, located at 2300 and $2400 \mathrm{~cm}^{-1}$ is shown beginning from about $240 \mathrm{sec}$ (at a temperature of about $127^{\circ} \mathrm{C}$ in the TGA tests) to the end. $\mathrm{CO}_{2}$ increased linearly to the top point of absorbance at about 960 $\sec \left(367^{\circ} \mathrm{C}\right)$, then decreased at about $1680 \mathrm{sec}\left(607^{\circ} \mathrm{C}\right)$ and kept the same concentration 

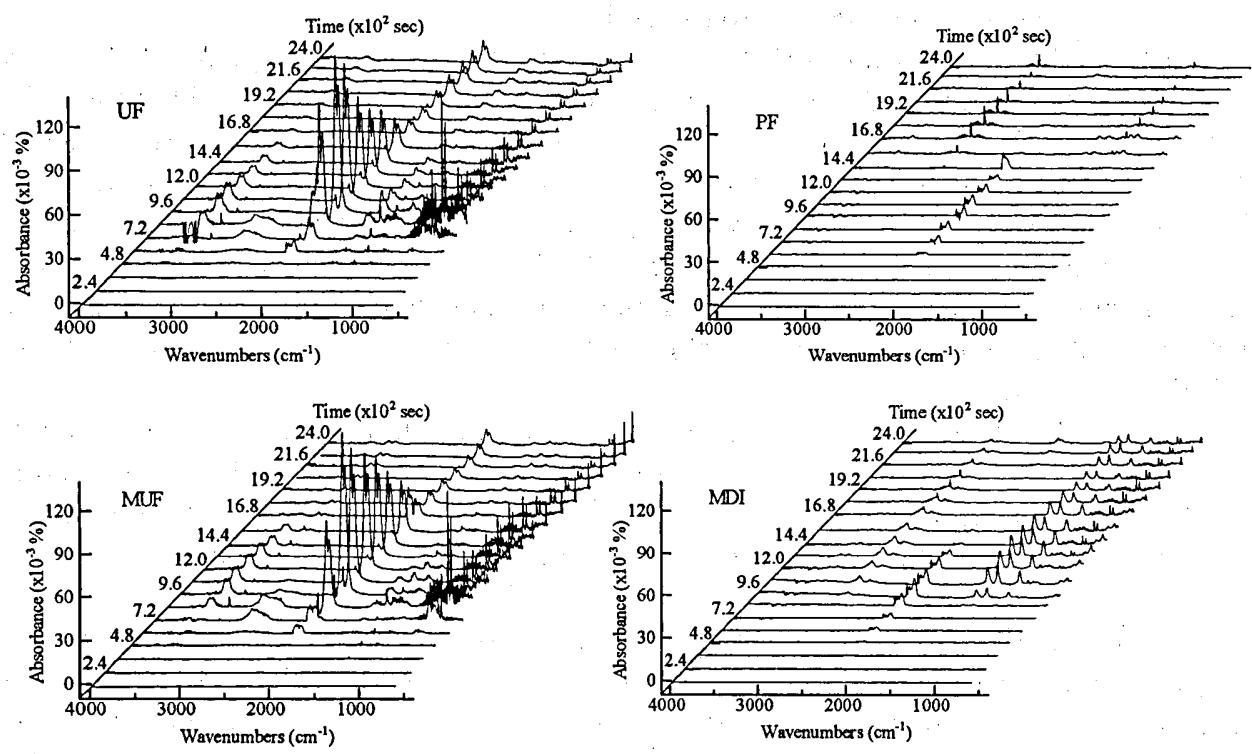

Fig. 3. TGA-IR spectra of 4 types of adhesives (UF, MUF, PF and MDI). Note: Abbreviations of UF, MUF, PF and MDI are the same as Figure 1.

of $\mathrm{CO}_{2}$ till the end of the tests. 3545 and $3509 \mathrm{~cm}^{-1}$ was assigned to the $\mathrm{N}-\mathrm{H}$ stretching of $\mathrm{NH}_{2}$ moieties (Zhu, 2001) from about $360 \mathrm{sec}\left(167^{\circ} \mathrm{C}\right)$ to the end. A higher concentration of $\mathrm{N}-\mathrm{H}$ stretching was seen between 840 and $1440 \mathrm{sec}\left(327\right.$ to $\left.527^{\circ} \mathrm{C}\right)$. The range from 480 to $1180 \mathrm{sec}\left(207\right.$ to $\left.440^{\circ} \mathrm{C}\right)$ showed a weak peak at 2921 and $2851 \mathrm{~cm}^{-1}$, respectively, which was attributed to the $\mathrm{C}-\mathrm{H}$ stretching of $\mathrm{CH}_{2}$ moieties. Another weak peak, at 1447 $\mathrm{cm}^{-1}$, was attributed to $\mathrm{C}-\mathrm{H}$ stretching of $\mathrm{CH}_{2}$ moieties, from $480 \mathrm{sec}$. The weak peaks at 1701 and $1625 \mathrm{~cm}^{-1}$ were assigned to the $\mathrm{C}=\mathrm{O}$ (carbonyl group), stretching from $480 \mathrm{sec}$ to the end. Moreover, several weak peaks at 972 or $962 \mathrm{~cm}^{-1}$ also emerged due to $\mathrm{C}=\mathrm{O}$ stretching, during the period from $480 \mathrm{sec}$ to the end. The top point of absorbance for $\mathrm{C}=\mathrm{O}$ stretching at 972 or $962 \mathrm{~cm}^{-1}$ was found at $960 \mathrm{sec}$, which was the same as the top point of absorbance for $\mathrm{CO}_{2}$.

TGA-IR spectra of MUF are shown in the bottom left of Fig. 3. The results indicated that UF and MUF present the same tendency in TGA-IR spectra (the left side of Fig. 3), as both belong to the same copolymer urea formaldehyde series. The results for the absorbance peak and the time location (including the decomposition temperature) of $\mathrm{CO}_{2}$, $\mathrm{N}-\mathrm{H}$ stretching, $\mathrm{C}-\mathrm{H}$ stretching and $\mathrm{C}=\mathrm{O}$ stretching for MUF were the same as for the TGA-IR spectra of UF; the $\mathrm{N}-\mathrm{H}$ deformation vibration of $\mathrm{NH}_{2}$ moieties was found at 1605 and $1649 \mathrm{~cm}^{-1}$, from about $360 \mathrm{sec}\left(167^{\circ} \mathrm{C}\right)$ to the end. The weak peak at $1449 \mathrm{~cm}^{-1}$ was attributed to $\mathrm{C}-\mathrm{H}$ deformation vibration of $\mathrm{CH}_{2}$ moieties, while at $1414 \mathrm{~cm}^{-1}$, it was assigned to $\mathrm{C}-\mathrm{N}$ stretching. Both of these began close to $480 \mathrm{sec}\left(207^{\circ} \mathrm{C}\right)$ to the end. A weak peak of $\mathrm{C}=\mathrm{O}$ stretching, located at $1736 \mathrm{~cm}^{-1}$, was also found from $600 \mathrm{sec}$ to the end $\left(247\right.$ to $\left.850^{\circ} \mathrm{C}\right)$. In addition, two weak peaks of triazine, located at 1365 and 
$1565 \mathrm{~cm}^{-1}$, began from about $480 \mathrm{sec}$ to the end.

For the TGA-IR spectra of PF (the top right of Fig. 3), the weak peaks of $\mathrm{CO}_{2}$ were also located at 2300 and $2400 \mathrm{~cm}^{-1}$ and began from about 600 to $1440 \mathrm{sec}\left(247\right.$ to $527^{\circ} \mathrm{C}$ ), almost disappearing towards the end of the tests. Some of weak board absorbance at 3300 to $3600 \mathrm{~cm}^{-1}$ was assigned to $\mathrm{OH}$ groups from about $720 \mathrm{sec}\left(287^{\circ} \mathrm{C}\right)$ to $2160 \mathrm{sec}$ $\left(767^{\circ} \mathrm{C}\right)$. A weak peak at $2980 \mathrm{~cm}^{-1}$ was assigned to out-of-plane bending of $\mathrm{C}-\mathrm{H}$ on the benzene (aromatic) ring, from $1440 \mathrm{sec}\left(527^{\circ} \mathrm{C}\right)$ to the end. The spectrum results in this study are similar to those reported by Reghunadhan Nair (2001). Another weak peak at $1100 \mathrm{~cm}^{-1}$ was attributed to the stretching vibration of benzene $\mathrm{C}-\mathrm{C}$, from $1560 \mathrm{sec}$ $\left(567^{\circ} \mathrm{C}\right)$ to the end.

The TGA-IR spectra of MDI are shown in the bottom right of Fig. 3. The results indicated that the two weak peaks of $\mathrm{CO}_{2}$ were the same for UF, MUF and MDI, located at 2300 and $2400 \mathrm{~cm}^{-1}$ and which began from about 480 to $1560 \mathrm{sec}\left(207\right.$ to $567^{\circ} \mathrm{C}$ ), almost disappearing towards the end of the tests. Some weak board absorbance located at $3700 \mathrm{~cm}^{-1}$, was assigned to $\mathrm{N}-\mathrm{H}$ stretching from about $600 \mathrm{sec}\left(247^{\circ} \mathrm{C}\right)$ to $1440 \mathrm{sec}$ $\left(527^{\circ} \mathrm{C}\right)$. In addition, some weak board absorbance, found at $3100 \mathrm{~cm}^{-1}$, was assigned to $\mathrm{OH}$ group, from about $960 \mathrm{sec}\left(367^{\circ} \mathrm{C}\right)$ to the end. Other weak peaks at $1624 \mathrm{~cm}^{-1}$ were assigned to $\mathrm{C}=\mathrm{O}$ (carbonyl group) stretching from $840 \mathrm{sec}\left(327^{\circ} \mathrm{C}\right)$ to the end. Two weak peaks at 972 or $927 \mathrm{~cm}^{-1}$ also emerged as $\mathrm{C}=\mathrm{O}$ stretching, from $1200 \mathrm{sec}\left(447^{\circ} \mathrm{C}\right)$. Results obtained also showed several weak peaks at 1114 and $1206 \mathrm{~cm}^{-1}$, which were assigned to the $\mathrm{C}-\mathrm{NH}$ group and $\mathrm{N}=\mathrm{C}$ group (Levchik, 1995) from $840 \sec \left(327^{\circ} \mathrm{C}\right)$ to the end, respectively.

To clarify the effectiveness of the analytical scale towards the four adhesives, and to identify the evolved compounds of each particular analysis, the most probable structures for the different polymers found in these adhesives (Chen, 1996), are included in Fig. 4., showed their typical molecular structures. UF analysis of the TGA-IR response showed that the thermal decomposition of the $\mathrm{NH}$ groups at a temperature of about $167^{\circ} \mathrm{C}$ was initially determined as a possible degradation species. The same results were previously reported in literature ( $\mathrm{Zhu}, 2001$ ). The $\mathrm{CH}_{2}$ and $\mathrm{C}=\mathrm{O}$ groups were then degraded at about $207^{\circ} \mathrm{C}$; the final contents of the char, therefore, were practically negligible $(5.40$ wt\%). Some of the MUF evolved species are the same as the UF evolved species, because they belong to the same series of copolymers. The TGA-IR results showed that the $\mathrm{N}-\mathrm{H}$ groups were degraded at a temperature of $167^{\circ} \mathrm{C}$, while the $\mathrm{CH}_{2}$ and triazine groups were degraded at $207^{\circ} \mathrm{C}$. In the case of $\mathrm{PF}$, the thermal decomposition of the $\mathrm{OH}$ groups was found to be significant at $287^{\circ} \mathrm{C}$, although it could be degraded earlier, at temperatures of 65 and $129^{\circ} \mathrm{C}$; this information was obtained from the results of the TGA tests. In addition, the $\mathrm{CH}_{2}$ groups were degraded at $527^{\circ} \mathrm{C}$ and the benzene $\mathrm{C}-\mathrm{C}$ at $567^{\circ} \mathrm{C}$. For MDI, the $\mathrm{C}=\mathrm{O}$ and $\mathrm{N}=\mathrm{C}$ groups were degraded at about $327^{\circ} \mathrm{C}$, which was analogous to the thermal decomposition of the OCN group during MDI pyrolysis, because of the resultant chemical reactions. Also, the char left at $850^{\circ} \mathrm{C}$ in the TGA tests for PF and MDI was 24.88 and $20.61 \mathrm{wt} \%$, respectively. The benzene (aromatic groups) structures for $\mathrm{PF}$ and MDI are of note in Fig. 4. That is, the thermal performance was enabled when the chemical compounds included aromatic groups. From these results, it may be concluded that still higher temperatures are needed for analysis of the char. Future study will continue in this direction. 


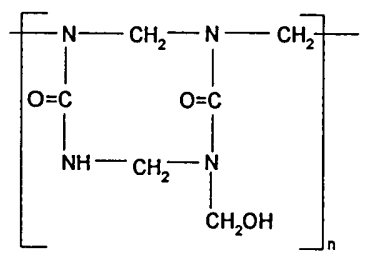

Urea formaldehyde resin adhesives (UF)

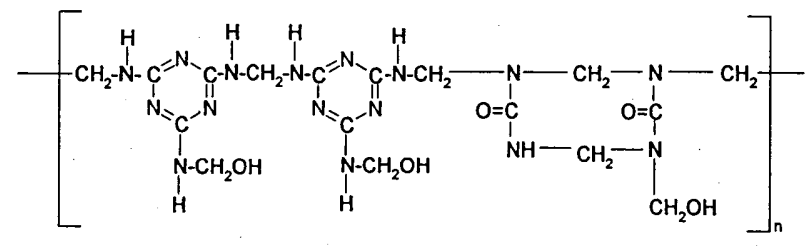

Melamine-urea formaldehyde copolymer resin adhesives (MUF)

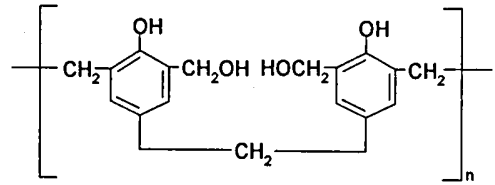

Phenol formaldehyde resin adhesives (PF)

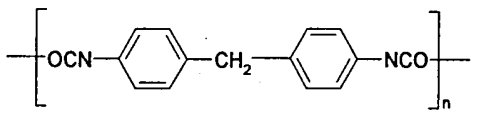

Diphenylmethane diisocyanate adhesives (MDI)

Fig. 4. Typical polymer molecular structure for 4 types of adhesives.

\section{Relationship of thermal decomposition and IR response of adhesives}

Because of these relationships between the TGA-IR spectra and the molecular structures of the adhesives, the authors of this study suggest that this experimental data can be used to reference the thermo-degradation processes of adhesives. Considering the sharp (decomposition) weight loss in the TGA tests and the IR response from the TGA-IR analysis, the relationships between the adhesives can be seen in Fig. 5. The maximum value (dotted line) of the four types of adhesives from the IR response in the TGA-IR tests, and the decomposition step (solid line) in accordance with the decomposition time in the TGA tests, found that the adhesives did not present the evolved species during the initial decomposition steps: UF at $448.6 \mathrm{sec}$, MUF at $410.1 \mathrm{sec}$, and PF at either 204.7 or $399.9 \mathrm{sec}$; nevertheless, they showed a significantly higher amount (concentration) of $\mathrm{CO}_{2}$ emitted during absorbance between 2300 and $2400 \mathrm{~cm}^{-1}$.

In combustion toxicology, $\mathrm{CO}_{2}$ is normally considered to be a significant toxicant and is also the best-known greenhouse gas, as it is capable of increasing the average global temperature, depending on the sensitivity of the atmosphere (such as the concentration of $\mathrm{CO}_{2}$ ) to greenhouse forcing. On the other hand, Goto (1969) reported that the shear-test strength of an adhesive bond by compression loading, for a structural laminated and glued wooden beam, under fire tests with several temperature points, obtained higher values for urea series resins (UF and MUF) than for others (PF and MDI). It can be concluded, therefore, that the fire resistance of UF and MUF is higher, because they both produce $\mathrm{CO}_{2}$ gas, which acts as a natural barrier, and slows down heat, during fire tests.

Results (Fig. 5) obtained also showed that both UF and MUF produced more kinds/higher concentrations of evolved species than PF and MDI; this was especially true for $\mathrm{PF}$, in which only a small quantity of $\mathrm{CO}_{2}$ was present at the maximum value of the IR spectra during $\mathrm{PF}$ pyrolysis. This infers that the ignition point and/or heat decomposition 

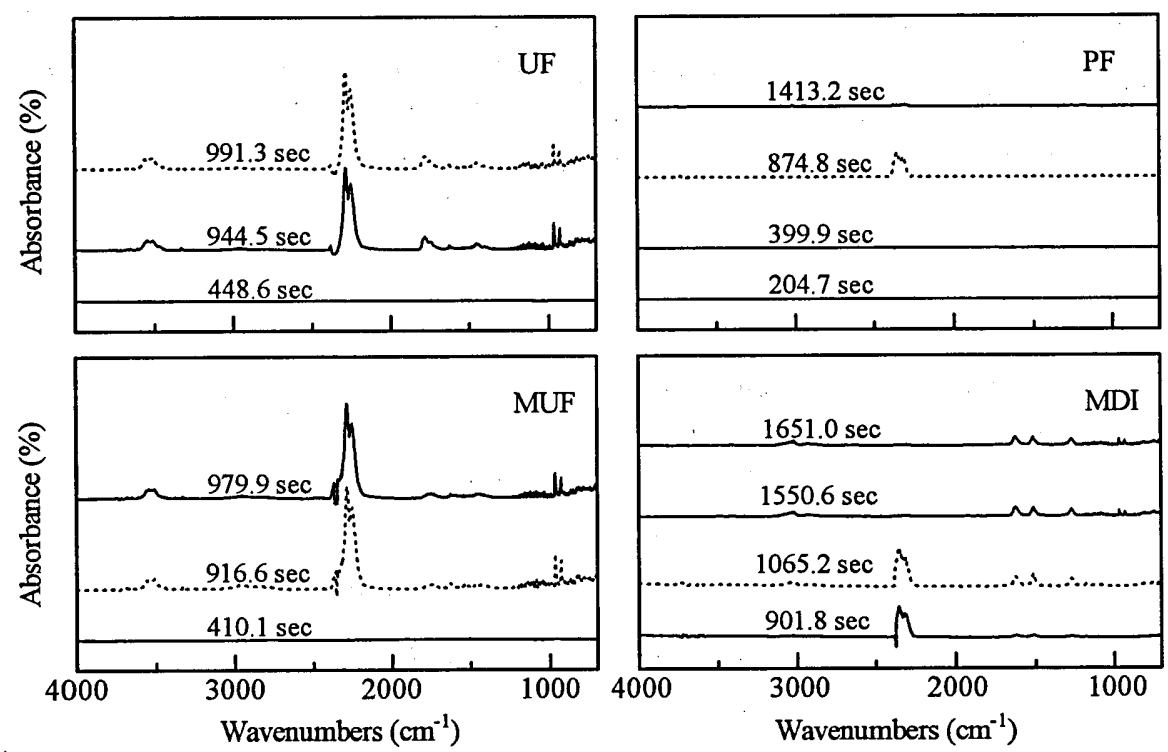

Fig. 5. IR spectra of 4 types of adhesives (UF, MUF, PF and MDI) at the maximum value of absorbance from IR response and at the decomposition steps of each adhesives.

Symbols: ......... Maximum value, - : decomposition step.

Note: Abbreviations of UF, MUF, PF and MDI are the same as Figure 1.

of the adhesives may influence their thermal behavior in relation to the extent and chemical nature of the smoke released during the burning process (Lin et al., 2001). Therefore, further identification of pyrolysis products may lead to useful results concerning the discard process of chemical synthesis compounds or principal component analysis, using combined methods, such as TGA-IR, with the basic molecular (influencing factors or composed elements) structure of materials or products, in addition to the adhesives, themselves.

\section{ACKNOWLEDGEMENTS}

The authors are grateful to the Oshika Shinko Co. Ltd., Japan for providing the experimental materials, the adhesives UF Resin-180, MUF PB-1230, MUF PF PB-1310 and MDI PB-1605, and to the PerkinElmer Corporation for sponsoring the experimental equipments, TGA-IR. We sincerely appreciate the assistance of professor Dr. Jin-Cherng HUANG, Department of Forest Products Science, National Chiayi University, Chiayi, Taiwan, ROC.

\section{REFERENCES}

Akiyama, T. 1998 Wood Recycles. Sunchoh Publication (Japan), pp. 7-29 
Baker, B. B., Jr. and M. A. Kaiser 1991 Understanding what happen in a fire. Anal. Chem., 63: 79-83

Camino, G., L. Costa and M. P. Luda 1993 Mechanistic aspects of intumescent fire retardant system. Makromol. Chem., Macromol. Symp., 74: 71-83

Chen, C. M. 1996 Wood adhesives. National Institute for Compilation and Translation (Taiwan, ROC), pp. $280-286$

Goto, K., S. Hoshino, K. Imaizumi and M. Yoshioka 1969 On the fire resistance of gluded laminated wooden beam. Wood technological Association of Japan, 24(12): 17-23

Hartzell, G. E. 1996 Overview of combustion toxicology. Toxicology, 155: 7-23

Hornsby, P. R. 1996 The application of hydrated mineral fillers as fire retardand and somke suppressing additives for polymers. Macromol. Symp., 108: 203-219

Hsu, C. K., K. B. Cheng and J. S. Lee 2000 The applications of the thermal analysis techniques on polymer materials. J. Spinning and Weaving Engineering, Taiwan ROC, 18: 43-58

Jang, Y. M. 1997 Waste Processing. WEN-JING Book Corp. (Taipei), pp. 49-85

Kercher, A. K. and D. C. Nagle 2001 TGA modeling of the thermal decomposition of CCA treated lumber waste. Wood Science and Technology, 35: 325-341

Kobayashi, N., M. Thikae and Y. Tominaga 2000 The properties and manufacture of renewable board from particleboard. In "Abstracts of the $50^{\text {th }}$ Annual Meeting of the Japan wood Research Society", Japan Wood Research Society, Kyoto, Japan, pp. 285

Kuwahara, M. 1996 Wood and Environment. Kasesya (Japan), pp. 29-32

Ladomersky, J. 2000 Emission analysis and minimization from the wood waste combustion. Drevarsky Vyskum, 45(4): 33-44

Levchik, S. V., G. Camino, M. P. Luda, L. Costa, B. Costes, Y. Henry, E. Morel and G. Muller 1995 Mechanistic study of thermal behavior and combustion performance of epoxy resin: I Homopolymerized TGDDM. Polymer for Advanced Technologies, 6(2): 53-62

Lin, H. C., J. C. Huang, Y. Fujimoto and Y. Murase 2001 Analysis of gases emitted from particleboard combustion. Forest Products Industries, 20(2): 165-174

Okuma, T. 1998 Wood-Based Resource Materials. Tokyo University Publication (Japan), pp. 17-20

Reghunadhan Nair, C. P., R. L. Bindu and K. N. Ninan 2001 Thermal characteristics of addition-cure phenolic resins. Polymer Degradation and Stability, 73: 251-257

Shibuwaza, R., R. Takano, H. Takarei, S. Kawamoto, M. Chen, O. Okuno and H. Chiba 2000 Performance and manufacture of board from the recycle of wood-based material (I). In "Abstracts of the $50^{\text {th }}$ Annual Meeting of the Japan wood Research Society", Japan Wood Research Society, Kyoto, Japan, pp. 286

Statheropoulos, M. and S. A. Kyriakou 2000 Quantitative thermogravimetric-mass spectrometric analysis for monitoring the effects of fire retardants on cellulose pyrolysis. Analytica Chimica Acta., 409: 203-214

Zhu, S. and W. Shi 2001 Hyperbranched polyurethane acrylates containing phosphate as radiation curable flame-retardant coating material. Conference Proceedings, China, pp. 108-114 